\title{
Peertechz
}

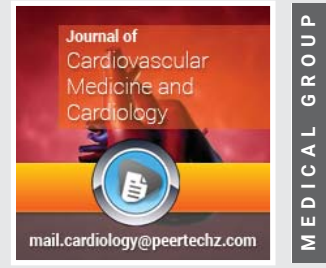

\section{Refractory electrical storm in coronary artery disease patient, challenges of dying heart}

\section{Rafid Fayadh Al-Aqeedi ${ }^{1 *}$, Goma Mauuf ${ }^{1}$ and Eiman $\mathrm{Nabi}^{2}$}

${ }^{1} \mathrm{MD}, \mathrm{MRCP}, \mathrm{FESC}, \mathrm{FACC}$, Heart Hospital, Hamad Medical Corporation, Doha, Qatar

${ }^{2} \mathrm{MBChB}$, Weill Cornell Medical College in Qatar, Qatar Foundation, Doha, Qatar
Received: 14 April, 2021

Accepted: 22 January, 2022

Published: 24 January, 2022

*Corresponding author: Rafid Fayadh Al-Aqeedi, MD, MRCP, FESC, FACC, Heart Hospital, Hamad Medical Corporation, POBox 3050, Doha, Qatar, Tel: +9647504718212; E-mail: rafayadh@yahoo.com

Keywords: Ventricular tachycardia; Electrical storm; Coronary artery disease; Electrical cardioversion; Shock; Anti-dysrhythmic drugs

Copyright License: (c) 2022 Al-Aqeedi RF, et al This is an open-access article distributed under the terms of the Creative Commons Attribution License, which permits unrestricted use, distribution, and reproduction in any medium, provided the original author and source are credited.

https://www.peertechzpublications.com

\section{Check for updates}

\section{Abstract}

Electrical storm most often occurs in patients with coronary artery disease and left ventricular dysfunction. We report a case of recurrent ventricular Tachycardia (VT) in a 49-year-old male patient previously known to have an inferior myocardial infarction and hypertension, presented with ischemic chest pain accompanied by dizziness, hypotension, and tachycardia. An electrocardiogram showed monomorphic VT. A prompt synchronized electrical cardioversion under sedation has reverted the rhythm to the sinus. An echocardiogram showed left ventricular segmental wall motion abnormalities and ejection fraction of $37 \%$. Then the condition complicated by recurrent $\mathrm{VT}$ necessitates multiple electrical cardioversions and defibrillation given for recurrent ventricular Fibrillation (VF) and short cardiopulmonary resuscitations that revived the patient from cardiac arrests. The patient had received a total of 103 electrical shocks over 15 days during which, he developed circulatory and respiratory compromise that required mechanical ventilation on twice occasions. Meticulous care including central monitoring and inotrope for hypotensive episodes was provided. A coronary angiogram showed normal left anterior descending and circumflex coronary arteries and a totally occluded right coronary artery which was failed to be revascularized in an attempt of angioplasty. The patient was successfully weaned off the ventilator and run a quiet course afterward. An implantable cardioverter-defibrillator was placed while maintained on oral amiodarone, mexiletine, metoprolol, and omega-3-acid ethyl esters, then discharged asymptomatic without recorded dysrhythmias. This case report underscores the challenges encountered throughout the management of such particular life-threatening ventricular arrhythmias and their impact on patient safety.

\section{Introduction}

The tumultuous nature which characterized the electrical storm is not unusually encountered in acute care facilities. It is known as clustering or hemodynamically destabilizing Ventricular Tachycardia (VT) or Ventricular Fibrillation (VF) that required multiple cardioversions or defibrillation within 24-hour. Refractory VT remains a poorly characterized disorder with a variety of etiologies. Failure to recover from these dysrhythmias by means of electrical cardioversion, or antiarrhythmic agents resulted in circulatory collapse carrying a high mortality rate. We present an unusual case of an electrical storm. The management and challenges encountered were discussed.

\section{Case report}

A 49-years old male, known with coronary artery disease and hypertension, presented with typical ischemic chest pain that was accompanied by palpitations, dizziness, diaphoresis, and visual blurring. The past medical history was relevant for inferior Myocardial Infarction (MI) 8-year previously, followed by coronary angiography which revealed a total right coronary artery occlusion. Physical examination showed Blood Pressure (BP) of $80 / 50 \mathrm{mmHg}$ and Heart Rate (HR) of 180 beats/ minute (bpm). Systemic examination was unremarkable. An Electrocardiogram (ECG) showed monomorphic VT (Figure 1). A prompt synchronized electrical cardioversion under sedation has reverted the rhythm to the sinus. The BP was improved to 90/60 $\mathrm{mmHg}$ and the HR record was $70 \mathrm{bpm}$. A repeated ECG showed Q waves in leads II, III, and aVF (Figure 2). Oral aspirin and clopidogrel were started together with Intravenous (IV) boluses of amiodarone and heparin followed by IV infusions. Beta-blocker was postponed until pressure improvement. Transthoracic echocardiography showed akinesia of inferior 

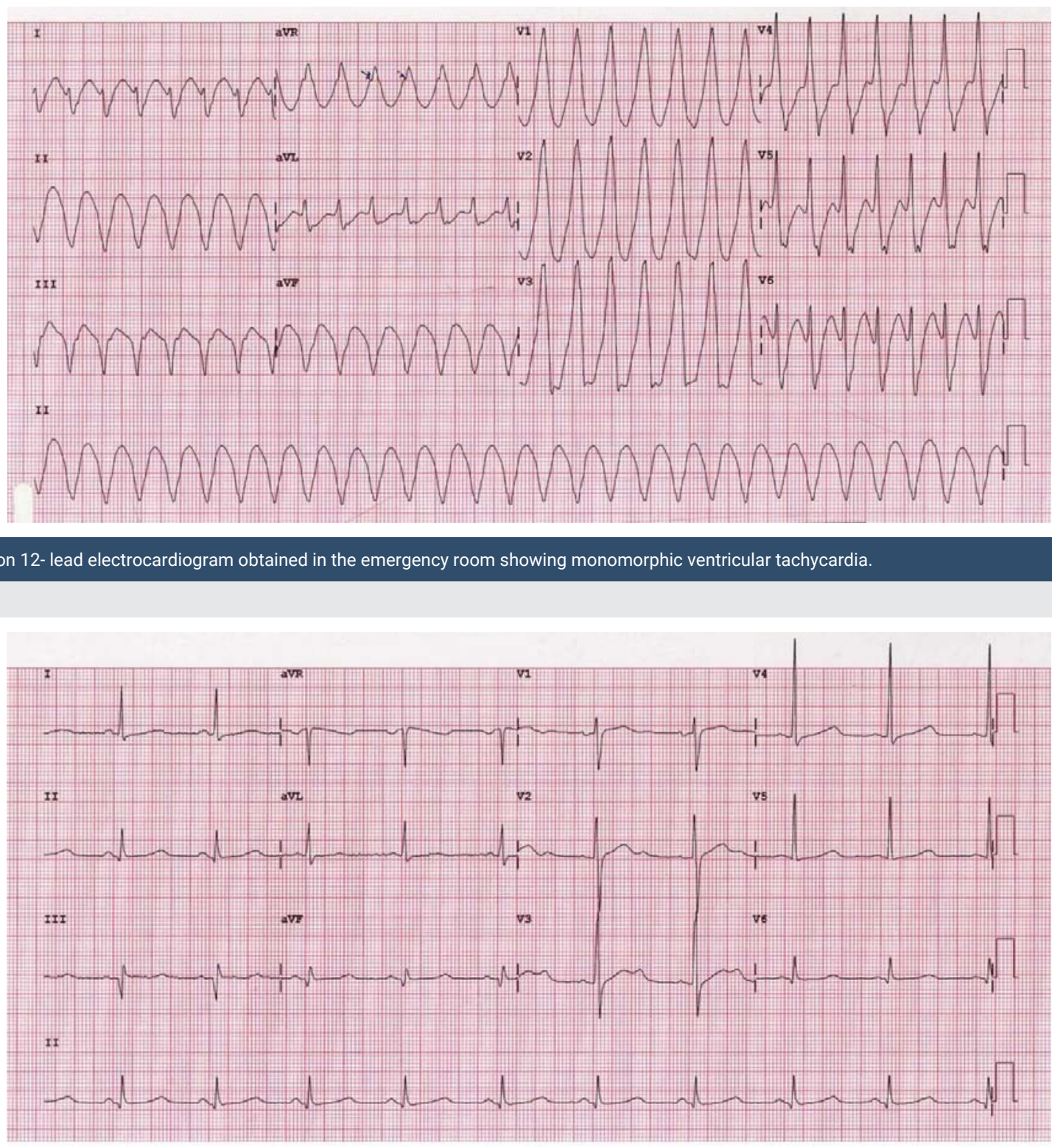

Figure 2: An electrocardiogram was obtained directly after a prompt synchronized electrical cardioversion showing sinus rhythm and old inferior myocardial infarction ( $Q$ waves in leads II, III, and aVF).

and posterior-lateral walls, a left ventricular ejection fraction of $37 \%$. Blood tests revealed elevated initial cardiac biomarkers which were perceived as a surge related to myocardial electrical injury. The blood levels of $\mathrm{Mg}^{2+}$ and $\mathrm{K}^{+}$were normal.

The following day, while the patient on an amiodarone infusion, he was developed VT that necessitate three shocks of 100J, the third shock resulted in Ventricular Fibrillation (VF). Then, the patient was revived after $360 \mathrm{~J}$ shock followed by short Cardiopulmonary Resuscitation (CPR). Shortly then, a new VT developed and shocked again twice with 100J. The seventh shock of 50J was given for one more VT and the subsequent 360J shock with short CPR followed for VF. His BP was maintained above $90 / 60 \mathrm{mmHg}$ and the HR above $65 \mathrm{bpm}$ while in sinus rhythm and sedation. Lidocaine IV infusion was started at this moment. The next morning, while the patient is stable with BP of $120 / 68 \mathrm{mmHg}$ and HR of $62 \mathrm{bpm}$, oral propranolol 10mg q8hr was started in addition to amiodarone. At noon the patient had an electrical storm. He received fifteen successive shocks and degenerated into VF twice before repossessing his sinus rhythm. The patient was sedated, mechanically ventilated. A few hours later the patient developed severe hypotension (BP 45/22mmHg) and bradycardia (HR 40bpm). Intravenous fluids, $2 \mathrm{mg}$ atropine, and inotrope were administered. Despite these measures, the patient is still hypotensive. Amiodarone and propranolol were held. While the BP and HR improved the following day. A coronary angiogram was performed on this day showing total ostial Right Coronary Artery (RCA) occlusion and normal left anterior descending and circumflex coronary arteries that give collaterals filling the distal RCA (Figure 3a). An attempt to open the totally occluded RCA was failed (Figure 3b).

During midnight, the patient developed a further episode of VT reverted to sinus rhythm with two shocks of 100J and $180 \mathrm{~J}$ respectively. Oral carvedilol $3.125 \mathrm{mg}$ q12hr was started. So 
far the patient had received twenty-six shocks over 3 days. The patient had no more VT over the next three days while the BP maintained above 100/60 and HR above 60bpm. Amiodarone IV infusion was restarted at $1 \mathrm{mg} / \mathrm{minute}$. His $\mathrm{Mg}^{2+}$ level was $2.94 \mathrm{mEq} / \mathrm{L}$ and $\mathrm{K}^{+} 3.8 \mathrm{mEq} / \mathrm{L}$. Intravenous potassium chloride and magnesium sulfate were given to keep serum $\mathrm{K}^{+}$above 4.0mEq/L and $\mathrm{Mg}^{2+}$ above 2.0mEq/L. ECG was in sinus rhythm and the corrected QT (QTc) interval was normal. Amiodarone was tapered down to $0.5 \mathrm{mg} / \mathrm{minute}$ on the following days. At present, almost one week elapsed from the time of admission. The patient was successfully weaned off the ventilator. The next day, the patient developed recurrent episodes of VT for which he received nineteen shocks and he was re-intubated again. Intravenous bolus amiodarone 300mg was given and esmolol infusion was started. The lidocaine infusion was increased to $2 \mathrm{mg} /$ minute. After uneventful next 24 hours, once again the IV amiodarone, esmolol, and midazolam were held as a consequence of severe hypotensive. The patient received a sum of twenty-seven more shocks for recurrent runs of VT over the next 48 hours. By now, the patient exceeds a full amount of $10 \mathrm{gm}$ of amiodarone. The QTc interval was $475 \mathrm{msec}$.

The patient developed nine more episodes of VT over the next three days while IV lidocaine and amiodarone infusion were reinstituted. The patient was still mechanically ventilated. Over the next 2 days, twenty-two more shocks were given for recurrent VT. Intravenous magnesium sulfate was given to correct hypomagnesemia $\left(\mathrm{Mg}^{2+} 0.95 \mathrm{mEq} / \mathrm{L}\right)$. The QTc interval was $557 \mathrm{msec}$. Lidocaine was reduced to $1 \mathrm{mg} / \mathrm{minute}$. The next 3 days were uneventful. His HR was maintained at around 65 bpm and BP above 120/60. The patient shows normal renal function. Serial ECGs showed sinus rhythm with a prolonged QTc interval of 500msec. Amiodarone was reduced to $0.5 \mathrm{mg} /$ min. Omega 3 fatty acids was started at $1 \mathrm{~g}$ daily along with oral mexiletine $200 \mathrm{mg}$ q12hr. The next day, the patient was successfully weaned off the ventilator. The QTc interval was $545 \mathrm{msec}$. The patient had received a total of 103 electrical cardioversion over a period of 15 days. Afterward, he run a quiet period of 2 weeks during which, an implantable cardioverterdefibrillator was placed in the left pectoral region (Figure 4) while maintained on oral amiodarone 200mg q12hr, mexiletine 200mg q12hr, metoprolol 50mg q12hr, and omega-3-acid ethyl esters 1gm a day in addition to oral aspirin, clopidogrel, and atorvastatin. The patient was discharged asymptomatic without recorded dysrhythmias.

\section{Discussion}

The risk of VT is highest during the first year (3-5\%) following acute MI [1], as well as the risk of sudden death from ventricular dysrhythmias remains high and may increase with time [2]. This patient developed MI several years before presentation, generally, the triggering mechanism for VT and particularly for ES is not well understood and it might be the main limitation for the development of a new clinically effective anti-dysrhythmic drug. However, it was thought to be a reentry around a fixed anatomical obstacle in the scar area that served as a substrate from which monomorphic VT originates. This dysrhythmogenic substrate may continue to be modified

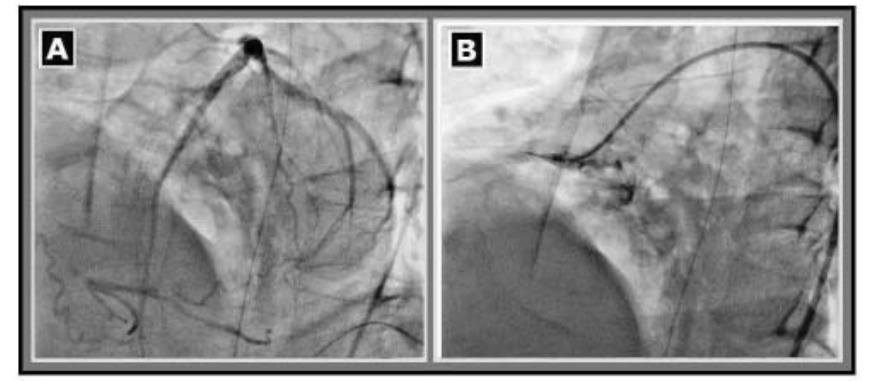

Figure 3: A. Coronary angiogram reveals normal left anterior descending and circumflex coronary arteries that give collaterals filling the distal right coronary artery (RCA). B. An attempted angioplasty failed to open the totally occluded RCA.

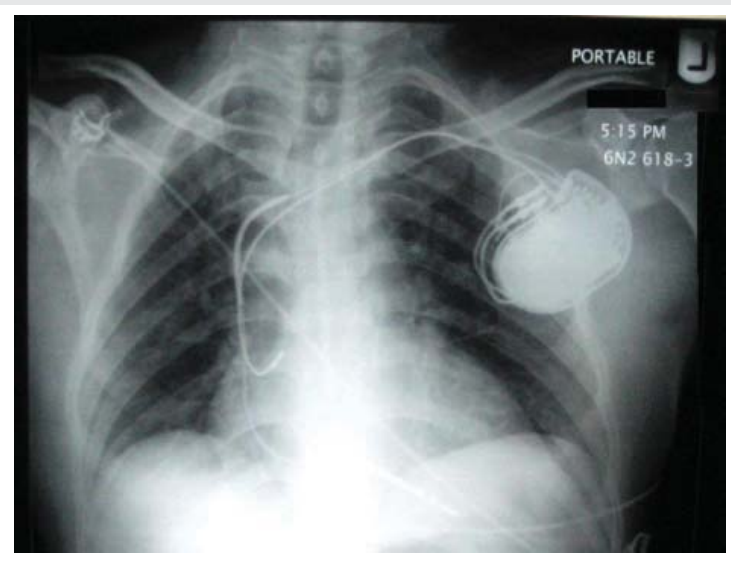

Figure 4: A chest $x$-ray was taken after the placement of an implantable cardioverterdefibrillator in the left pectoral region.

by subsequent ischemic insults as well as late ventricular remodeling and worsening pump function that may contribute to prodysrhythmias in addition to the other precipitants of ES including hypokalemia, hypocalcemia hypomagnesemia, and hypotension.

While, termination of VT is typically achieved with Direct Current (DC) cardioversion, anti-dysrhythmic drugs, or overdrive ventricular pacing and correction of electrolyte disturbances, such therapies are not always successful as in the present case [3]. Unfortunately, sparse clinical trials information is present to guide the choice of anti-dysrhythmic therapy in these patients. Amiodarone Intravenously (IV) is recommended as first-line anti-dysrhythmic therapy in hemodynamically tolerated monomorphic VT [4]. It showed unequivocal superiority over IV lidocaine with head-to-head comparison [5]. However, this patient continued to have monomorphic VT while on IV amiodarone with episodes of hypotension especially when IV lidocaine was added. There were no placebo-controlled trials that addresses the effectiveness of amiodarone in terminating hemodynamically tolerated monomorphic VT. The available case series included patients who had structural heart disease with moderately impaired Left Ventricular Ejection Fraction (LVEF), mainly secondary to ischemic heart disease suggests a low termination rate of $29 \%$ to $42 \%$ [6-8] after administration of $150 \mathrm{mg}$ and $300 \mathrm{mg}$ IV amiodarone. Besides, there is no clinical trial evidence that IV magnesium is useful for treating or preventing sustained monomorphic VT in the absence of QT prolongation. In addition to amiodarone, nifekalant, and combined vasopressin and 
adrenaline have been proposed for these extreme situations, but, they have had only $40 \%$ to $60 \%$ success rates [9-11]. On the other hand, beta-blocker therapy has been shown to reduce both the incidence of VF and mortality in acute MI [12,13]. A pooled database from 2 randomized clinical trials evaluated the use of amiodarone in patients recovering from MI, cardiac death, and dysrhythmic death or resuscitated cardiac arrest, was significantly lower in patients receiving amiodarone, compared to placebo ( $P<0.05$ and 0.03 , respectively), if they were also receiving beta-blockers $[14,15]$. This patient had a better response to this combination of therapy. The QT interval was not exceeded $500 \mathrm{msec}$, yet, we accept some kind of prolongation while the patient is in amiodarone infusion.

The LV function is a well-established independent risk factor for sudden cardiac death in patients with ventricular dysrhythmias $[16,17]$. In a sub-analysis of the Candesartan in Heart Failure Assessment of Reduction in Mortality and Morbidity (CHARM) study, evaluation of the impact of LVEF quartiles on long-term survival revealed a 39\% relative risk of increased mortality for every $10 \%$ reduction in LVEF [18]. In the present case, the lower LVEF was a contributory factor for the ES occurrence, which might be aggravated by worsening function or new ischemic insult. Patients who present with sustained VT and an LVEF $<35 \%$ should be considered for an implantable defibrillator. A meta-analysis of the secondary prevention internal cardioverter-defibrillator (ICD) trials revealed that the patients who benefited from ICD therapy over amiodarone therapy were patients with $\mathrm{EF}<35 \%$. Amiodarone was equivalent to ICD in patients with $\mathrm{EF}>35 \%$ [19].

The primary goal for long-term management in patients who have presented with sustained VT is to prevent recurrence of VT and sudden death. Ablation can be useful to prevent or reduce recurrent episodes of VT, usually as adjunctive therapy to an ICD. The risks are greater, and mortality remains significant after ablation in these patients with recurrent, drug-refractory VT. Attention to optimizing treatment of the underlying disease, as well as controlling VT recurrences, seems prudent. Reddy et al showed the outcomes may be better in patients undergoing ablation after initial presentation with VT [20]. We believed, VT ablation may also be considered in this patient before undergoing ICD implantation, but it was not feasible because of unstable hemodynamic status [21]. On the other hand, angiography revealed a totally occluded right coronary artery, though an attempt of revascularization was failed to open the artery, because of the chronic nature of the lesion.

The patient was moved from IV esmolol to oral metoprolol. Mexiletine was given instead of lidocaine as it shares the same anti-dysrhythmic class properties and is reported to be helpful in some refractory ventricular dysrhythmias. We believe, mexiletine, was helpful in this patient in weaning off lidocaine. It was confirmed that mexiletine preferentially depresses conduction in the diseased myocardium at the VT origin, and this action occurred at a higher rate during VT $[22,23]$. Moreover, some studies may support its safety as an anti-dysrhythmic effect, omega- 3 polyunsaturated fatty acids added despite the equivocal evidence against ventricular arrhythmia.

Finally, there is no recommended clinical protocol to treat such unusual cases, however, treatment of ES, although intricately successful in this patient, is hardly a momentous event in the medical firmament, but it is hoped that the challenges faced and meticulous care given may trigger possible alternative therapies for ES and further investigation.

\section{Conclusion}

Despite the modern fibrinolytic and interventional therapies, ES is still uncommonly encountered in emergency practice. It's a striking and potentially treatable clinical entity. Physicians should act promptly in management and to correct all possible etiological and precipitating factors.

\section{References}

1. Andreson D, Bethge KP, Boissel JP, von Leitner ER, Peyrieux JC, et al. (1990) Importance of quantitative analysis of ventricular arrhythmias for predicting the prognosis in low-risk postmyocardial infarction patients. European Infarction Study Group. Eur Heart J. 11: 529-536. Link: https://bit.ly/3ImvVUM

2. Wilber D, Wojciech Z, Hall WJ, Brown MW, Lin AC, et al. (2004) Time dependence of mortality risk and defibrillator benefit after myocardial infarction. Circulation 109: 1082-1084. Link: https://bit.ly/3AoguJ3

3. Marill KA, deSouza IS, Nishijima DK, Stair TO, Setnik GS, et al. (2006) Amiodarone is poorly effective for the acute termination of ventricular tachycardia. Ann Emerg Med 47: 217-224. Link: https://bit.ly/32li6Xp

4. Zipes DP, Camm AJ, Borggrefe M, Buxton AE, Chaitman B, et al. (2006) ACC/ $\mathrm{AHA} / / \mathrm{ESC} 2006$ guidelines for management of patients with ventricular arrhythmias and the prevention of sudden cardiac death. Circulation 144 e385-e484. Link: https://bit.ly/3qMzL3M

5. Dorian P, Cass D, Schwartz B, Cooper R, Gelaznikas R, et al. (2002) Amiodarone as compared with lidocaine for shock-resistant ventricular fibrillation. $N$ Engl $J$ Med 346: 884-890. Link: https://bit.ly/3nKdUrW

6. Marill KA, deSouza IS, Nishijima DK, Stair TO, Setnik GS, et al. (2006) Amiodarone is poorly effective for the acute termination of ventricular tachycardia. Ann Emerg Med 47: 217-224. Link: https://bit.ly/3nKdUbq

7. Tomlinson DR, Cherian P, Betts TR, Bashir Y (2008) Intravenous amiodarone for the pharmacological termination of haemodynamically-tolerated sustained ventricular tachycardia: is bolus dose amiodarone an appropriate first-line treatment? Emerg Med J 25: 15-18. Link: https://bit.ly/3tPzb75

8. Schutzenberger W, Leisch F, Kerschner K, Harringer W, Herbinger W (1989) Clinical efficacy of intravenous amiodarone in the short-term treatment of recurrent sustained ventricular tachycardia and ventricular fibrillation. $\mathrm{Br}$ Heart J 62: 367-371.Link: https://bit.ly/33DELyV

9. Washizuka T, Chinushi M, Watanabe H, Hosaka Y, Komura S, et al. (2005) Nifekalant hydrochloride suppresses severe electrical storm in patients with malignant ventricular tachyarrhythmias. Circ J 69: 1508-1513. Link: https://bit.ly/3rCXxOV

10. Grmec S, Mally S (2006) Vasopressin improves outcome in out-of-hospital cardiopulmonary resuscitation of ventricular fibrillation and pulseless ventricular tachycardia: An observational cohort study. Crit Care 10: R13. Link: https://bit.ly/3ImvU3a

11. Kudenchuk PJ, Cobb LA, Copass MK, Cummins RO, Doherty AM, et al. (1999) Amiodarone for resuscitation after out of-hospital cardiac arrest due to ventricular fibrillation. N Engl J Med 341: 871-878. Link: https://bit.ly/3nNcdK 
12. Rossi PR, Yusuf S, Ramsdale D, Furze L, Sleight P (1983) Reduction of ventricular arrhythmias by early intravenous atenolol in suspected acute myocardial infarction. BMJ (Clin Res Ed) 286: 506-510. Link: https://bit.ly/3nMRh68

13. Ryden L, Ariniego R, Arnman K, Herlitz D, Hjalmarson A, et al. (1983) A doubleblind trial of metoprolol in acute myocardial infarction. Effect on ventricular tachyarrhythmias. N Engl J Med 308: 614-618. Link: https://bit.ly/3KAb2ra

14. Boutitie F, Boissel JP, Connolly SJ, Camm AJ, Cairns JA, et al. (1999) Amiodarone interaction with beta-blockers: analysis of the merged EMIAT (European Myocardial Infarct Amiodarone Trial) and CAMIAT (Canadian Amiodarone Myocardial Infarction Trial) databases. The EMIAT and CAMIAT Investigators. Circulation 99: 2268-2275. Link: https://bit.ly/35ij0Fv

15. Nademanee K, Taylor R, Bailey WE, Rieders DE, Kosar EM (2000) Treating electrical storm: sympathetic blockade versus advanced cardiac life supportguided therapy. Circulation 102: 742-747. Link: https://bit.ly/3tPBYgW

16. Curtis JP, Sokol SI, Wang Y, Rathore SS, Ko DT, et al. (2003) The association of left ventricular ejection fraction, mortality, and cause of death in stable outpatients with heart failure. J Am Coll Cardiol 42: 736-742. Link: https://bit.ly/3tPKOGr

17. Caruso AC, Marcus FI, Hahn EA, Hartz VL, Mason JW (1997) Predictors of arrhythmic death in the ESVEM trial. Electrophysiologic Study Versus Electromagnetic Monitoring. Circulation 96: 1888-1892. Link: https://bit.ly/3AjRTFn
18. Solomon SD, Anavekar N, Skali H, McMurray JJ,, Swedberg K, et al. (2005) Influence of ejection fraction on cardiovascular outcomes in a broad spectrum of heart failure patients. Circulation 112: 3738-3744. Link: https://bit.ly/3AolOLe

19. Connolly SJ, Hallstrom AP, Cappato R, Schron EB, Kuck KH, et al. (2000) Metaanalysis of the implantable cardioverter defibrillator secondary prevention trials. Eur Heart J 21: 2071-2207. Link: https://bit.ly/3fMSMgk

20. Reddy VY, Reynolds MR, Neuzil P, Richardson AW, Taborsky M, et al. (2007) Prophylactic catheter ablation for the prevention of defibrillator therapy. $\mathrm{N}$ Engl J Med 357: 2657-2665. Link: https://bit.ly/33XZI7k

21. Venkataraman G, Strickberger SA (2011) The role of ventricular tachycardia ablation in the reduction of implantable defibrillator shocks. Heart Fail Clin 7 207-213. Link: https://bit.ly/3IxMxt7

22. Aizawa Y, Abe A, Ohira K, Furushima H, Chinushi M, et al. (1996) Preferential action of mexiletine on central common pathway of reentrant ventricular tachycardia. J Am Coll Cardiol 28: 1759-1764. Link: https://bit.ly/3nMN1DD

23. Moak JP, Smith RT, Garson A (1987) Mexiletine: An Effective Antiarrhythmic Drug for Treatment of Ventricular Arrhythmias in Congenital Heart Disease. $J$ Am Coll Cardiol 10: 824-829. Link: https://bit.ly/3nNLOXN
Discover a bigger Impact and Visibility of your article publication with

\section{Peertechz Publications}

\section{Highlights}

* Signatory publisher of ORCID

* Signatory Publisher of DORA (San Francisco Declaration on Research Assessment)

* Articles archived in worlds' renowned service providers such as Portico, CNKI, AGRIS, TDNet, Base (Bielefeld University Library), CrossRef, Scilit, J-Gate etc.

* Journals indexed in ICMJE, SHERPA/ROMEO, Google Scholar etc.

* OAI-PMH (Open Archives Initiative Protocol for Metadata Harvesting)

* Dedicated Editorial Board for every journa

* Accurate and rapid peer-review process

* Increased citations of published articles through promotions

* Reduced timeline for article publication

Submit your articles and experience a new surge in publication services (https://www.peertechz.com/submission).

Peertechz journals wishes everlasting success in your every endeavours.

Citation: Al-Aqeedi RF, Mauuf G, Nabi E (2022) Refractory electrical storm in coronary artery disease patient, challenges of dying heart. J Cardiovasc Med Cardio 9(1): 001-005. DOI: https://dx.doi.org/10.17352/2455-2976.000176 